\title{
Estrogen therapy to treat retinopathy in newborn mice
}

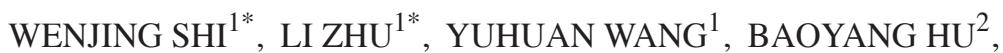 \\ HONGLEI XIAO ${ }^{2}$, GUOMING ZHOU ${ }^{2}$ and CHAO CHEN $^{1}$ \\ ${ }^{1}$ Department of Neonatology, Children's Hospital of Fudan University, Shanghai 201102; \\ ${ }^{2}$ Department of Human Anatomy, Histology and Embryology, Fudan University, Shanghai 200032, P.R. China
}

Received January 14, 2015; Accepted May 21, 2015

DOI: $10.3892 / \mathrm{etm} .2015 .2554$

\begin{abstract}
The aim of the present study was to treat retinopathy of prematurity $(\mathrm{ROP})$ with estrogen $\left(\mathrm{E}_{2}\right)$ so as to elucidate the role of $\mathrm{E}_{2}$ in the pathogenesis of ROP. A total of 120 postnatal 7-day-old (P7) C57BL/6J mice were selected and raised in a high-oxygen environment (75\% oxygen) for 5 days, followed by 5 days in normal room air. Different doses of $E_{2}$ or normal saline (NS) were injected intraperitoneally during different time-periods, and the mice were divided into 14 groups according dose of $\mathrm{E}_{2}$ injection $(0.5-1.5 \mu \mathrm{g} / 0.05 \mathrm{ml})$ and dosing time. Blood vessel changes and hyperplasia were evaluated in flat-mounted retina and retinal slices. All mice that were exposed to room air, whether they were administered $\mathrm{E}_{2}$ or NS, showed good vascular development in the flat-mounted retina at P17. No increase in the number of endothelial cell nuclei in the new blood vessels was observed. In ascending order of $E_{2}$ dose the numbers of cell nuclei were as follows: $0.18 \pm 0.129$, $0.28 \pm 0.086$ and $0.55 \pm 0.110$. The number in the NS group was $2.12 \pm 0.373$. When the results of the room-air groups were compared with those of the hyperoxia groups, a highly significant difference was found in each comparison $(\mathrm{P}<0.0001)$. All mice showed varying degrees of neovascularization and vascular obstruction in the flat-mounted retina at P17, and it was difficult to compare the blood vessels morphologically among these groups. The number of endothelial cell nuclei decreased following $\mathrm{E}_{2}$ injection, and the difference from the NS group exposed to hyperoxia was highly significant $(\mathrm{P}<0.0001)$. For all dose levels, the number of cell nuclei was the lowest when the drug was administered during P7-16, and the difference from the other two time-periods was statistically significant $(\mathrm{P}<0.05)$. When $\mathrm{E}_{2}$ was administered during $\mathrm{P} 7-16$, the number of cell nuclei was $15.5 \pm 1.993$ in the $0.5-\mu \mathrm{g}$ group, $14.23 \pm 2.49$ in the $1.0-\mu \mathrm{g}$ group and $18.05 \pm 1.62$ in the
\end{abstract}

Correspondence to: Dr Chao Chen, Department of Neonatology, Children's Hospital of Fudan University, 399 Wanyuan Road, Shanghai 201102, P.R. China

E-mail: chen6010@163.com

*Contributed equally

Key words: retinopathy of prematurity, estrogen, neovascularization
1.5- $\mu$ g group. No significant difference was found among these three groups $(\mathrm{P}>0.05)$. In conclusion, $\mathrm{E}_{2}$ treatment during the development of retinopathy can improve symptoms in neonatal mice, suggesting that $\mathrm{E}_{2}$ plays an important role at the two initial stages in the pathogenesis of ROP. This may indicate new pharmacological measures to prevent and treat ROP.

\section{Introduction}

Retinopathy of prematurity (ROP) affects premature infants and is a major cause of blindness and visual impairement despite continous improvements in neonatal care (1). There are 250,000 very low birth weight (VLBW) infants born in China every year. Among these VLBW, 30,000 will develop ROP, and $\sim 10,000$ receive ophthalmological surgery (2). As reported in the International Classification of Retinopathy of Prematurity $(3,4)$ and a multi-center clinical trial on retinopathy of prematurity (ROP) (5-9), current treatments for ROP mainly include cryotherapy and laser photocoagulation for threshold ROP, as well as sclera buckling and vitrectomy at a later stage. Although these procedures do significantly reduce the long-term adverse outcomes of ROP, such as blindness and retinal detachment, they may cause permanent damage to the retinal structure and are associated with life-long eye problems, including visual field defects and refractive error (10-13). Researchers have, therefore, increasingly focused on preventing ROP progression by inhibiting angiogenesis based on the pathogenesis of ROP (14-23). Two distinct phases have been identified: Phase I, involving delayed retinal vascular growth after premature birth; and phase II, concerning uncontrolled proliferative growth of retinal blood vessels. Such approaches have been proven feasible in animal experiments; however, angiogenesis inhibitors may also inhibit normal vascular development and hinder normal ocular anatomical and functional development $(24,25)$. These problems remain unresolved. Furthermore, neither surgical procedures nor angiogenesis inhibitors are capable of preventing the occurrence of ROP, since they are measures taken after the development of ocular lesions.

Estrogen $\left(E_{2}\right)$, or $17 \beta$-estradiol, can act on vascular cells and neurons and plays an important role in retinal vascular development. Estrogen receptor (ER)-mediated $E_{2}$ is particularly important in normal retinal vascular development and the pathogenesis of ROP (26-32). Preterm infants are prone 
to develop ROP, possibly due to the unique metabolism of $\mathrm{E}_{2}$ in these infants. Early $E_{2}$ replacement administered prior to the occurrence of abnormal vascular lesions may, therefore, promote the development of normal blood vessels and thereby improve the prognosis for ROP. This provides a novel idea for preclinical and clinical trials and may help validate the role of $E_{2}$ and $E R$ in normal retinal vascular development and the pathogenesis of ROP from the perspective of treatment.

\section{Materials and methods}

Experimental animals. A total of 120 healthy 7-day-old C57BL/6J mice of either gender were selected. The mice were not weaned and were raised with lactating female rats. These were clean-grade animals that were provided by the Department of Anatomy, Histology and Embryology of Fudan University Shanghai Medical College (Shanghai, China). The study protocol was approved by the university Animal Care and Use Committee and conformed to international standards for the humane treatment of experimental animals.

Materials and instruments. The $\mathrm{E}_{2}$ used in the study was estr a-1,3,5(10)-triene-3,17 $\beta$-diol (Sigma-Aldrich, St. Louis, MO, USA). The molecular formula was $\mathrm{C}_{18} \mathrm{H}_{24} \mathrm{O}_{2}$ and the molecular weight was $272.4 \mathrm{Da}$. We customized a 50x40x25-cm glass container with three round holes in the lid. Of the three holes, one was for inserting an air inlet pipe connecting the oxygen cylinder and the nitrogen cylinder, one was an air outlet hole and the remaining hole was connected to an oxygen analyzer. The bottom of the container was covered in soda lime to keep the container dry. A common mouse cage was placed in the container. The room temperature was maintained at $23 \pm 2{ }^{\circ} \mathrm{C}$ and room luminosity did not exceed 300 Lux with illumination for $12 \mathrm{~h}$ a day.

\section{Experimental methods}

Grouping. In the study group, ROP was induced in C57BL/6 mice by exposing postnatal 7-day-old (P7) mice to $75 \%$ oxygen (hyperoxia) for 5 days, followed by 5 days in normal room air. The mice in the control group were raised in room air for 10 days. The mice in the control and hyperoxia groups received an intraperitoneal injection of either $E_{2}$ or normal saline (NS) once per day and were further grouped according to the administered agent, dose and dosing time, as shown in Table I.

Flat mounting. The flat-mounted retinas were prepared as follows. For the three groups with an injection time of P7-11, retinas were separated and flat-mounted on the slides on days 0, 2 and 5 (i.e., P12, 14 and 17), respectively, after the mice were removed from the oxygen container. Six eyes were enucleated at each time-point from 6 mice. For the remaining groups, 6 eyes were enucleated from 6 mice, and the flat-mounted retinas were prepared on $\mathrm{P} 17$ to observe the profile of retinal vascular development and proliferation. The specific method of retina flat-mounting and ADPase enzyme histochemistry is as detailed below. For anesthesia, the mice received a peritoneal injection of 2,2,2-tribromoethanol (Avertin ${ }^{\circledR} ; 0.5 \mathrm{ml} / 15 \mathrm{~g}$; Sigma-Aldrich). For perfusion, the chest cavity of each mouse was opened and the heart was exposed. Through an infusion needle inserted in the left ventricle, NS was infused for 2-3 min followed by infusion of $4 \%$ paraformaldehyde solution for $\sim 5 \mathrm{~min}$. The eyeballs of the mice were enucleated and fixed in $4 \%$ paraformaldehyde solution. For sampling, the limbus was cut open circularly at $1 \mathrm{~mm}$ posterior to the limbus. The cornea was removed and the lens was extracted. Four to five radial incisions were made using the optic papilla as the center. The sclera and choroid were removed, and the vitreous body and the retinal pigment epithelial layer were removed by a brush. The samples were then rinsed with 0.05 mol Tris-maleate buffer (pH 7.2; Sigma-Aldrich) five times (15 min each time). Next, the samples were incubated in the reaction solution at $37^{\circ} \mathrm{C}$ for $15 \mathrm{~min}$. For color development, the samples were reacted with $10 \%$ (1:10) ammonium sulfide for $5 \mathrm{~min}$. The results were observed with an optical microscope.

Preparation and observation of paraffin sections. Six eyes of 6 mice were collected from each group. The mice were sacrificed by cervical dislocation 5 days after the removal of the mice from the oxygen container. The eyeballs were enucleated and directions were marked. For fixation, the enucleated eyeball was placed in $4 \%$ paraformaldehyde solution and fixed for $24 \mathrm{~h}$. Samples were dehydrated with gradient alcohol and made transparent with xylene. The samples were then embedded in soft paraffin, hard paraffin I and hard paraffin II for $30 \mathrm{~min}, 1 \mathrm{~h}$ and $1 \mathrm{~h}$, respectively. Serial sections of $6 \mu \mathrm{m}$ were sliced parallel to the sagittal plane from the cornea to the optic papilla. Slices were then flattened in warm water and mounted on their slide. The samples were dewaxed with xylene and dehydrated with gradient alcohol. Conventional hematoxylin and eosin staining was then performed. Finally, an optical microscope was used to observe the results.

Endothelial cell nucleus count. The endothelial cell nucleus count in the new retinal blood vessels was performed as follows. Ten pathological slices were taken intermittently from each eyeball. The interval between two adjacent sections was $60 \mu \mathrm{m}$ (10 slices). The endothelial cell nuclei of the blood vessels that broke through the internal limiting membrane of the retina were counted by section and by eyeball. Only the cell nuclei of blood vessels near the internal limiting membrane, rather than those of blood vessels in the vitreous cavity not associated with the internal limiting membrane, were counted.

Statistical analysis. All data were analyzed with the statistical analysis software SPSS 11.0 for Windows (SPSS, Inc., Chicago, IL, USA). Analysis of variance was used to compare the number of nuclei in the endothelial cells of new blood vessels that broke through the internal limiting membrane among the groups. $\mathrm{P}<0.05$ was considered to indicate a statistically significant difference.

\section{Results}

Vascular morphological changes following $E_{2}$ treatment. No retinal vascular abnormalities were observed at P17 in the normal mice that received various doses of $\mathrm{E}_{2}$ or NS between P7 and 16. All blood vessels were mature, and the larger vessels had more branches with consistently large lumen. The surrounding small vessels were well developed, forming a vascular arch at the edge of the retina. The branching structure of the superficial vascular network and the polygonal mesh-like structure of the deep vascular network 
Table I. Experimental grouping for $\mathrm{E}_{2}$ therapy.

\begin{tabular}{|c|c|c|c|c|c|}
\hline Group & Number of mice & Drug & Dose & Normal air or oxygen & Time of injection \\
\hline 1 & 6 & $\mathrm{E}_{2}$ & $0.5 \mu \mathrm{g} / 0.05 \mathrm{ml}$ & Normal air & P7-16 \\
\hline 2 & 18 & $\mathrm{E}_{2}$ & $0.5 \mu \mathrm{g} / 0.05 \mathrm{ml}$ & Oxygen inhalation & P7-11 \\
\hline 3 & 6 & $\mathrm{E}_{2}$ & $0.5 \mu \mathrm{g} / 0.05 \mathrm{ml}$ & Oxygen inhalation & P7-16 \\
\hline 4 & 6 & $\mathrm{E}_{2}$ & $0.5 \mu \mathrm{g} / 0.05 \mathrm{ml}$ & Oxygen inhalation & P12-16 \\
\hline 5 & 6 & $\mathrm{E}_{2}$ & $1.0 \mu \mathrm{g} / 0.05 \mathrm{ml}$ & Normal air & P7-16 \\
\hline 6 & 18 & $\mathrm{E}_{2}$ & $1.0 \mu \mathrm{g} / 0.05 \mathrm{ml}$ & Oxygen inhalation & P7-11 \\
\hline 7 & 6 & $\mathrm{E}_{2}$ & $1.0 \mu \mathrm{g} / 0.05 \mathrm{ml}$ & Oxygen inhalation & P7-16 \\
\hline 8 & 6 & $\mathrm{E}_{2}$ & $1.0 \mu \mathrm{g} / 0.05 \mathrm{ml}$ & Oxygen inhalation & P12-16 \\
\hline 9 & 6 & $\mathrm{E}_{2}$ & $1.5 \mu \mathrm{g} / 0.05 \mathrm{ml}$ & Normal air & P7-16 \\
\hline 10 & 18 & $\mathrm{E}_{2}$ & $1.5 \mu \mathrm{g} / 0.05 \mathrm{ml}$ & Oxygen inhalation & P7-11 \\
\hline 11 & 6 & $\mathrm{E}_{2}$ & $1.5 \mu \mathrm{g} / 0.05 \mathrm{ml}$ & Oxygen inhalation & P7-16 \\
\hline 12 & 6 & $\mathrm{E}_{2}$ & $1.5 \mu \mathrm{g} / 0.05 \mathrm{ml}$ & Oxygen inhalation & P12-16 \\
\hline 13 & 6 & NS & $0.05 \mathrm{ml}$ & Normal air & P7-16 \\
\hline 14 & 6 & NS & $0.05 \mathrm{ml}$ & Oxygen inhalation & P7-16 \\
\hline
\end{tabular}

$\mathrm{E}_{2}$, estrogen; NS, normal saline; $\mathrm{P}$, postnatal day.
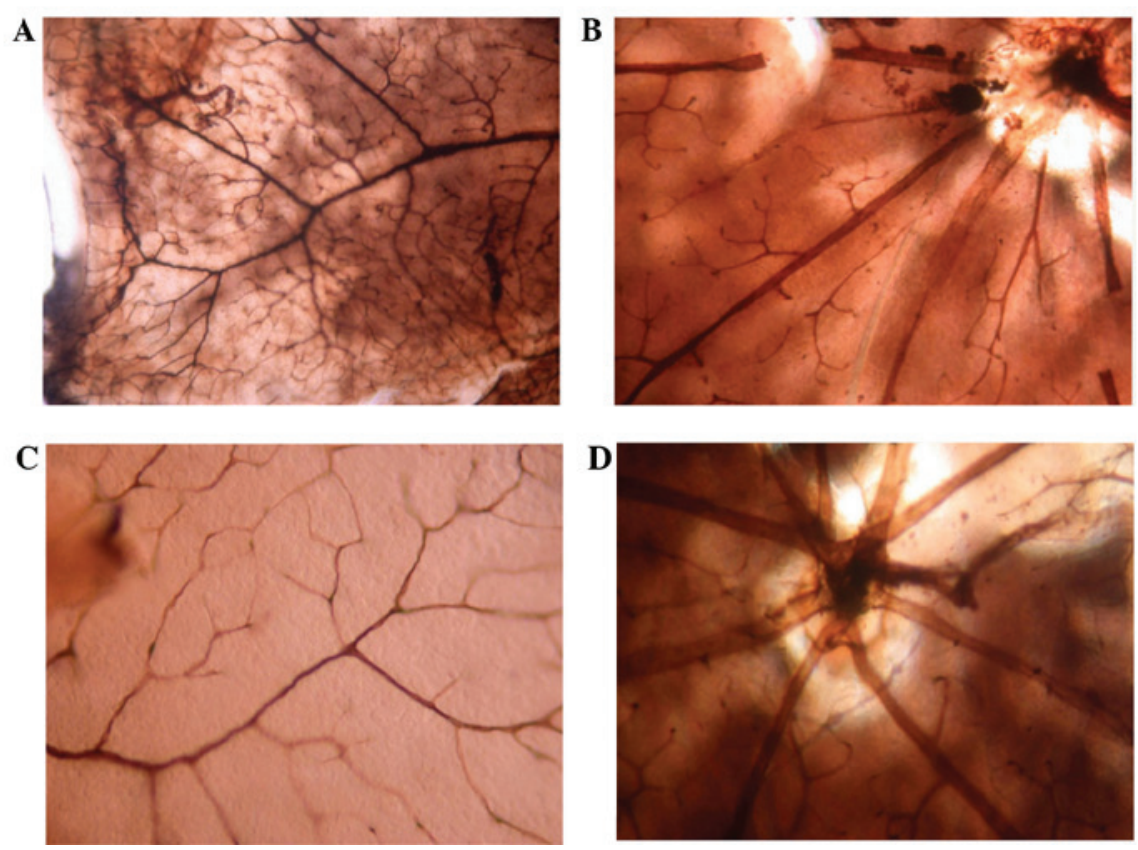

Figure 1. No retinal vascular abnormalities were observed at postnatal day 17 (P17) in the normal mice that received (A) $0.5 \mu \mathrm{g}$ estrogen ( $\mathrm{E}_{2}$ ), (B) $1 \mu \mathrm{g} \mathrm{E}_{2}$, (C) $1.5 \mu \mathrm{g} \mathrm{E}$ or (D) $0.05 \mathrm{ml}$ normal saline between P7 and P16 (magnification, x100-200).

could be clearly noted, and no blood vessel obstruction was observed (Fig. 1).

Mice receiving oxygen supplement consistently showed retinal neovascularization following NS injection or injection of $\mathrm{E}_{2}$ at varying doses during different periods. On P12, non-perfusion areas at the center of the retina, poorly-branched large vessels with a narrow lumen and naïve surrounding small vessels were observed. On P14, neovascularization was found at the interface between the vascularized zone and the non-vascularized zone. On P17, the number of new vessels had increased, and the two-tier vascular network had lost its normal structure, with accompanying vascular obstruction. The number of blood vessels or the size of the central non-perfusion area could not be compared morphologically among the different groups.

Quantification of angiogenesis following treatment. The effect of $E_{2}$ treatment on angiogenesis was quantified by counting the endothelial cell nuclei of the blood vessels that broke through the internal limiting membrane of the retina. It was found that, following both $\mathrm{E}_{2}$ and NS injection, the number of nuclei in the normal mice was low, and pair-wise comparison revealed 

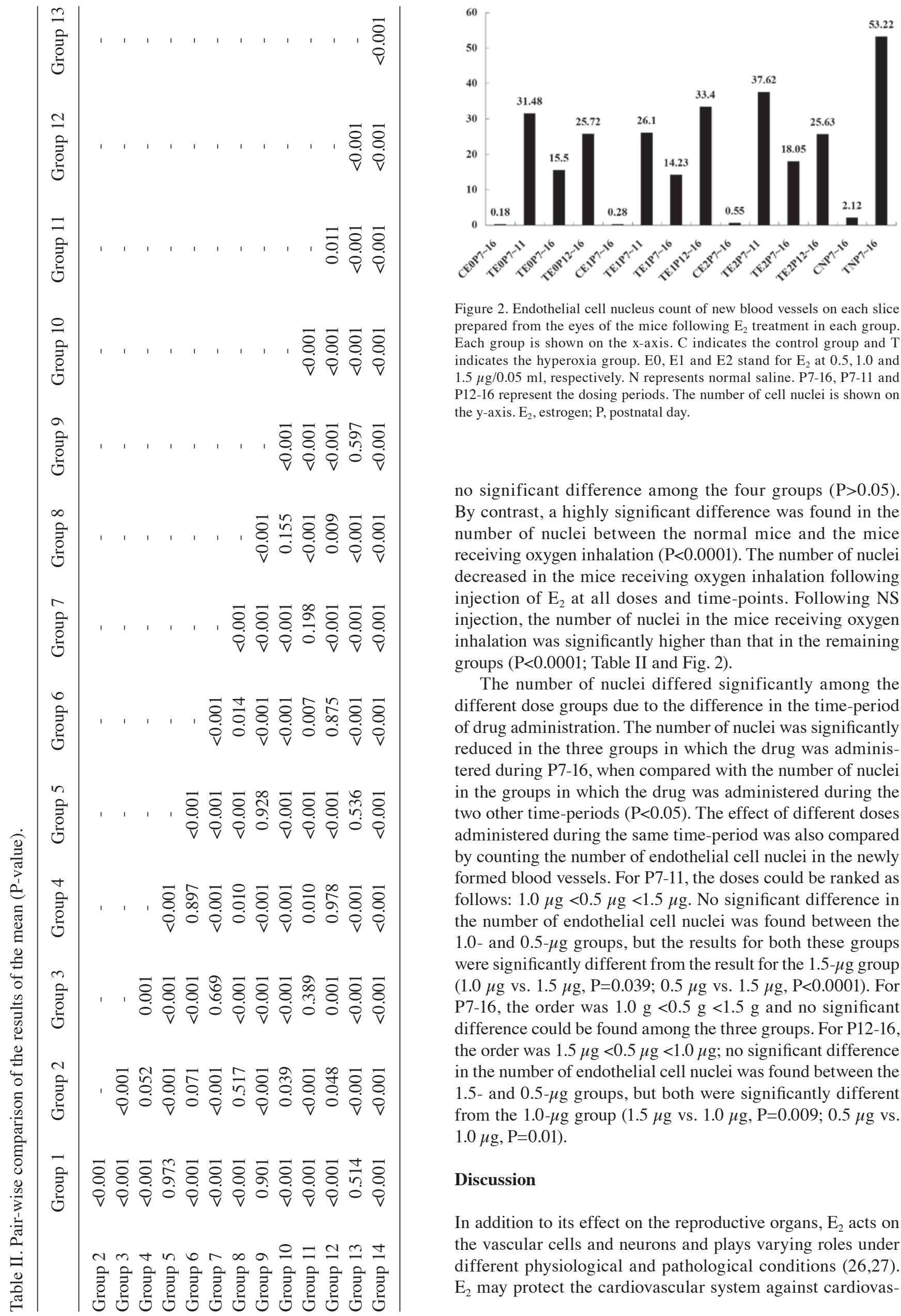

Figure 2. Endothelial cell nucleus count of new blood vessels on each slice prepared from the eyes of the mice following $\mathrm{E}_{2}$ treatment in each group. Each group is shown on the $\mathrm{X}$-axis. $\mathrm{C}$ indicates the control group and $\mathrm{T}$ indicates the hyperoxia group. E0, E1 and E2 stand for $\mathrm{E}_{2}$ at $0.5,1.0$ and $1.5 \mu \mathrm{g} / 0.05 \mathrm{ml}$, respectively. $\mathrm{N}$ represents normal saline. P7-16, P7-11 and P12-16 represent the dosing periods. The number of cell nuclei is shown on the $y$-axis. $E_{2}$, estrogen; $P$, postnatal day.

no significant difference among the four groups $(\mathrm{P}>0.05)$. By contrast, a highly significant difference was found in the number of nuclei between the normal mice and the mice receiving oxygen inhalation $(\mathrm{P}<0.0001)$. The number of nuclei decreased in the mice receiving oxygen inhalation following injection of $E_{2}$ at all doses and time-points. Following NS injection, the number of nuclei in the mice receiving oxygen inhalation was significantly higher than that in the remaining groups $(\mathrm{P}<0.0001$; Table II and Fig. 2).

The number of nuclei differed significantly among the different dose groups due to the difference in the time-period of drug administration. The number of nuclei was significantly reduced in the three groups in which the drug was administered during P7-16, when compared with the number of nuclei in the groups in which the drug was administered during the two other time-periods $(\mathrm{P}<0.05)$. The effect of different doses administered during the same time-period was also compared by counting the number of endothelial cell nuclei in the newly formed blood vessels. For P7-11, the doses could be ranked as follows: $1.0 \mu \mathrm{g}<0.5 \mu \mathrm{g}<1.5 \mu \mathrm{g}$. No significant difference in the number of endothelial cell nuclei was found between the 1.0- and $0.5-\mu \mathrm{g}$ groups, but the results for both these groups were significantly different from the result for the 1.5- $\mu \mathrm{g}$ group $(1.0 \mu \mathrm{g}$ vs. $1.5 \mu \mathrm{g}, \mathrm{P}=0.039 ; 0.5 \mu \mathrm{g}$ vs. $1.5 \mu \mathrm{g}, \mathrm{P}<0.0001)$. For P7-16, the order was $1.0 \mathrm{~g}<0.5 \mathrm{~g}<1.5 \mathrm{~g}$ and no significant difference could be found among the three groups. For P12-16, the order was $1.5 \mu \mathrm{g}<0.5 \mu \mathrm{g}<1.0 \mu \mathrm{g}$; no significant difference in the number of endothelial cell nuclei was found between the $1.5-$ and $0.5-\mu \mathrm{g}$ groups, but both were significantly different from the $1.0-\mu \mathrm{g}$ group $(1.5 \mu \mathrm{g}$ vs. $1.0 \mu \mathrm{g}, \mathrm{P}=0.009 ; 0.5 \mu \mathrm{g}$ vs. $1.0 \mu \mathrm{g}, \mathrm{P}=0.01$ ).

\section{Discussion}

In addition to its effect on the reproductive organs, $E_{2}$ acts on the vascular cells and neurons and plays varying roles under different physiological and pathological conditions $(26,27)$. $\mathrm{E}_{2}$ may protect the cardiovascular system against cardiovas- 
cular diseases, such as hypertension and atherosclerosis, by dilating blood vessels and increasing blood flow (28). $\mathrm{E}_{2}$ may increase the activity of endothelial cells, inhibit endothelial cell apoptosis, promote endothelial cell proliferation, facilitate angiogenesis and the growth of blood vessels and play an important role in retinal vascular development $(29,30,33)$. In vivo, $\mathrm{E}_{2}$ shows its specific effects only subsequent to binding to ER $(31,32)$. Basic endothelial cell-derived nitric oxide may dilate blood vessels and prevent thrombosis by inhibiting platelet aggregation, a process that may be regulated by ER (34). In a previous study, we found that ER-mediated $E_{2}$ plays an important role in normal retinal vascular development and ROP pathogenesis (35). Maternal $\mathrm{E}_{2}$ levels during pregnancy may increase by $\sim 100$-fold $(33,35-39)$. Fetal $\mathrm{E}_{2}$ levels increase with gestational age, with the $\mathrm{E}_{2}$ concentration peaking between 33 and 36 weeks of pregnancy. $E_{2}$ levels drop rapidly after birth and may reach normal neonatal levels at $24 \mathrm{~h}$; therefore, since preterm infants are delivered early, their $E_{2}$ levels are lower than those of full-term infants. $E_{2}$ levels drop more rapidly and fluctuate more in preterm infants than those in full-term neonates, which may explain why such infants are prone to ROP (36). Theoretically, early supplementation of exogenous $\mathrm{E}_{2}$ would facilitate vascular development and thereby prevent severe retinal hypoxia and subsequent cascade reactions.

In the present study it was found that the number of endothelial cell nuclei in the newly formed blood vessels was reduced significantly in all the three groups receiving $\mathrm{E}_{2}$ treatment compared with those receiving NS $(\mathrm{P}<0.0001)$, suggesting that $\mathrm{E}_{2}$ replacement therapy did have beneficial effects; however, $\mathrm{E}_{2}$ did not inhibit angiogenesis completely, and it was difficult to compare angiogenesis in the flat-mounted retinas among the different groups based on morphology alone. In the tissue sections in which nuclei could be counted, the nucleus count was significantly different from that of the normal mice $(\mathrm{P}<0.0001)$, indicating that, to some extent, $\mathrm{E}_{2}$ plays a role in the development and progression of ROP. $\mathrm{E}_{2}$ may be involved in this process by promoting the expression of the VEGF gene (39), resulting in the formation of a large number of new blood vessels. Miyamoto et al (30) found that retinal angiogenesis was reduced in ROP mice following intraperitoneal injection of $E_{2}$ during $\mathrm{P} 7-11$. They hypothesized that $\mathrm{E}_{2}$ supplementation at the hyperoxia stage would partially restore the expression of the $V E G F$ gene, promoting the growth of retinal blood vessels and thereby alleviating hyperoxia-induced retinal injury. Miyamoto et al observed that in the subsequent hypoxia phase, $\mathrm{E}_{2}$ supplementation at the same dose on P12-16 also reduced angiogenesis. Furthermore, when the drug was administered during P7-16, the number of endothelial cell nuclei in the new blood vessels was the lowest, suggesting that $\mathrm{E}_{2}$ may inhibit angiogenesis via other mechanisms. Transient blocking of the middle cerebral artery can cause retinal ischemia in adult female Sprague Dawley rats, and terminal deoxynucleotidyl transferase-mediated dUTP nick end labeling staining showed a significantly increased number of apoptotic cells in the ganglion cell layer at $1 \mathrm{~h}$ after ischemia (40). $\mathrm{E}_{2}$ treatment can completely reverse such apoptosis (40), suggesting that $\mathrm{E}_{2}$ has neuroprotective effects when the retina is in a low oxygenation state. This may explain the reduced angiogenesis following $\mathrm{E}_{2}$ administration during P12-16 and P7-16.
In the present study, the experimental animals were divided into 14 groups according to dosage and dosing period. The dosing periods were the same as those in the study by Miyamoto et al (30), as dosing in those periods can exactly reflect the effect of dosing simultaneously or separately in the two phases of ROP development and progression, determine the treatment window and provide a preclinical basis for potential clinical application in the future. Furthermore, elucidating the roles of $\mathrm{E}_{2}$ and its receptor $\mathrm{ER}$ at different stages of ROP pathogenesis may reveal the optimal mode of treatment. Three dosage groups, $0.5,1.0$ and $1.5 \mu \mathrm{g}$, were selected. The doses of 1.0 and $1.5 \mu \mathrm{g}$ represent the upper and lower limits of the dosage for $E_{2}$ replacement therapy in menopausal women (0.25-0.5 mg/day), respectively, and were determined by dose conversion between different species (41). While the two higher doses are within the physiological range, the lower dose of $0.5 \mu \mathrm{g}$ is below the physiological range. It was found that, for each dose, maximal inhibitory effects were achieved when the drug was administered during P7-16, which was consistent with the results of Miyamoto et al (30). The results support a potential therapeutic benefit of $E_{2}$ at the two stages of ROP pathogenesis. The incidence of blindness in diabetic men aged $<45$ years is higher than that in diabetic women of the same age, and the incidence is similar in men and women aged $>45$ years, suggesting that $E_{2}$ may improve the prognosis of diabetic retinopathy (42). Diabetic retinopathy and ROP have a similar pathogenesis, which may further support our view that $\mathrm{E}_{2}$ plays an important role in retinal development and ROP pathogenesis in premature infants and holds promise as a potential treatment for ROP.

The present study additionally compared the effects of different doses of $\mathrm{E}_{2}$ administered at different time-periods. It was found that the number of nuclei in the high-dose group $(1.5 \mu \mathrm{g})$ was greatest when the drug was administered at P7-11; at this time-period, the difference from the other two dose groups was highly significant. The results did not demonstrate the superiority of a high dose. The number of nuclei did not differ significantly between the 1.0 - and $0.5-\mu \mathrm{g}$ groups when the drug was administered during P7-16, although the number in the $1.0-\mu \mathrm{g}$ hypoxia group was slightly lower. It is therefore suggested that $E_{2}$ replacement therapy may achieve the maximum effect even at a low dose $(1.0 \mu \mathrm{g}) . \mathrm{E}_{2}$ has a long history of clinical application. It has been used widely in menopausal and postmenopausal women, since it may improve menopausal symptoms and osteoporosis and provide skin care effects; however, misuse and abuse of $\mathrm{E}_{2}$, particularly overdose of $\mathrm{E}_{2}$, may increase the incidence of uterine and breast cancer $(28,43) . \mathrm{E}_{2}$ should therefore be appropriately used under the supervision of healthcare professionals and with the close monitoring of blood levels.

A number of clinical trials have evaluated $E_{2}$ replacement therapy in premature infants (29,31-33). Extremely low birth weight neonates with an average gestational age of 26.6 weeks and a birth weight of $675 \mathrm{~g}$ received $\mathrm{E}_{2}$ supplementation at an intravenous dose of $2.3 \mathrm{mg} / \mathrm{kg} / \mathrm{day}$. If the intravenous infusion could not be maintained, transepidermal administration was used instead. The total duration of treatment was 6 weeks to maintain the plasma $\mathrm{E}_{2}$ at the intrauterine level (33). The neonates were followed-up until 15 months of corrected gestational age (34). Following drug administration, the uterine volume, 
breast, weight, length and head circumference of the neonates showed a transient increase and the bone mineral deposition rate trended towards an increase $(33,35)$. The incidence of chronic lung diseases decreased and complications of the central nervous system were reduced $(33,35)$. Although the administered dose was very high and no long-term follow-up or any multi-center clinical trial is yet available, the results remain encouraging.

The present study demonstrated that $E_{2}$ is important in the normal development of retinal blood vessels and the pathogenesis of ROP and has evident efficacy in the prevention and treatment of ROP. Although $\mathrm{E}_{2}$ may not completely prevent the occurrence of ROP, it may at least alleviate ROP and thereby reduce the incidence of long-term complications, such as blindness and refractive errors. This effect of $E_{2}$ is of great significance to individuals and society and may provide significant economic benefits. In addition, due to the special metabolism of $E_{2}$ in preterm infants, $E_{2}$ supplementation not only facilitates retinal development but also improves the development of several other systems, which may result in a significant improvement in the prognosis of preterm infants and their future quality of life. Despite this, a number of steps are still required to translate these results from animal studies into eventual clinical application, including rigorous clinical trials and long-term follow-up studies, in order to determine the pharmacokinetics, dose, dosing regimen and schedule and assess the efficacy, safety and side effects.

In conclusion, $\mathrm{E}_{2}$ plays an important role in retinal vascular development and the pathogenesis of ROP in mice. $\mathrm{E}_{2}$ replacement therapy may alleviate retinal disease in neonatal mice, and intraperitoneal injection of $\mathrm{E}_{2}$ at a dose of $1.0 \mu \mathrm{g}$ during P7-16 achieved the best efficacy in mice; however, the long-term efficacy and side effects of $\mathrm{E}_{2}$ require further study.

\section{Acknowledgements}

This study was sponsored by the Foundation for Doctoral Degrees of Fudan University.

\section{References}

1. Chen $J$ and Smith LE. Retinopathy of prematurity. Angiogenesis 10: 133-140, 2007.

2. Li Z and Ni WJ: Advances of biological drugs for retinal neovascularization. Guo Ki Yan Ke Za Zhi 7: 1119-1123, 2007 (In Chinese).

3. No authors listed: An international classification of retinopathy of prematurity. Pediatrics 74: 127-133, 1984.

4. No authors listed: An international classification of retinopathy of prematurity. II. The classification of retinal detachment. The International Committee for the Classification of the Late Stages of Retinopathy of Prematurity. Arch Ophthalmol 105: 906-912, 1987.

5. Cryotherapy for Retinopathy of Prematurity Cooperative Group: Multicenter trial of cryotherapy for retinopathy of prematurity. Preliminary results. Arch Ophthalmol 106: 471-479, 1988.

6. Cryotherapy for Retinopathy of Prematurity Cooperative Group: Multicenter trial of cryotherapy for retinopathy of prematurity. Three-month outcome. Arch Ophthalmol 108: 195-204, 1990.

7. Cryotherapy for Retinopathy of Prematurity Cooperative Group: Multicenter trial of cryotherapy for retinopathy of prematurity. One-year outcome - structure and function. Arch Ophthalmol 108: 1408-1416, 1990.

8. Cryotherapy for Retinopathy of Prematurity Cooperative Group: Multicenter trial of cryotherapy for retinopathy of prematurity. 3 1/2-year outcome - structure and function. Arch Ophthalmol 111: 339-344, 1993.
9. Cryotherapy for Retinopathy of Prematurity Cooperative Group: Multicenter trial of cryotherapy for retinopathy of prematurity. Snellen visual acuity and structural outcome at $51 / 2$ years after randomization. Arch Ophthalmol 114: 417-424, 1996.

10. Greven CM and Tasman W: Rhegmatogenous retinal detachment following cryotherapy in retinopathy of prematurity. Arch Ophthalmol 107: 1017-1018, 1989.

11. Ben-Sira I, Nissenkorn I, Weinberger D, Shohat M, Kremer I, Krikler R and Reisner SH: Long-term results of cryotherapy for active stages of retinopathy of prematurity. Ophthalmology 93: 1423-1428, 1986.

12. Quinn GE, Miller DL, Evans JA, Tasman WE, McNamara JA and Schaffer DB: Measurement of Goldmann visual fields in older children who received cryotherapy as infants for threshold retinopathy of prematurity. Arch Ophthalmol 114: 425-428, 1996.

13. Biglan AW, et al: Progress in ROP research. Chin J Med 1: 7-13, 1990.

14. Ma DH, Chen JK, Zhang F, Lin KY, Yao JY and Yu JS: Regulation of corneal angiogenesis in limbal stem cell deficiency. Prog Retin Eye Res 25: 563-590, 2006.

15. Mintz-Hittner HA, Kennedy KA and Chuang AZ; BEAT-ROP Cooperative Group: Efficacy of intravitreal bevacizumab for stage 3+ retinopathy of prematurity. N Engl J Med 364: 603-615, 2011.

16. Miki K, Miki A, Matsuoka M, Muramatsu D, Hackett SF and Campochiaro PA: Effects of intraocular ranibizumab and bevacizumab in transgenic mice expressing human vascular endothelial growth factor. Ophthalmology 116: 1748-1754, 2009.

17. Yatoh S, Kawakami Y, Imai M, Kozawa T, Segawa T, Suzuki H, Yamashita K and Okuda Y: Effect of a topically applied neutralizing antibody against vascular endothelial growth factor on corneal allograft rejection of rat. Transplantation 66: 1519-1524, 1998.

18. Moshfeghi DM and Berrocal AM: Retinopathy of prematurity in the time of bevacizumab: Incorporating the BEAT-ROP results into clinical practice. Ophthalmology 118: 1227-1228, 2011.

19. O'Reilly MS, Boehm T, Shing Y, Fukai N, Vasios G, Lane WS, Flynn E, Birkhead JR, Olsen BR and Folkman J: Endostatin: An endogenous inhibitor of angiogenesis and tumor growth. Cell 88: 277-285, 1997.

20. Suzuma K, Takagi H, Otani A, Oh H and Honda Y: Expression of thrombospondin-1 in ischemia-induced retinal neovascularization. Am J Pathol 154: 343-354, 1999.

21. Coughlin SR: Thrombin signaling and protease-activated receptors. Nature 407: 258-264, 2000.

22. Shafiee A, Penn JS, Krutzsch HC, Inman JK, Roberts DD and Blake DA: Inhibition of retinal angiogenesis by peptides derived from thrombospondin-1. Invest Ophthalmol Vis Sci 41: 2378-2388, 2000.

23. LonchamptM,PennelLandDuhaultJ:Hyperoxia/normoxia-driven retinal angiogenesis in mice: A role for angiotensin II. Invest Ophthalmol Vis Sci 42: 429-432, 2001.

24. Falavarjani KG and Nguyen QD: Adverse events and complications associated with intravitreal injection of anti-VEGF agents: A review of literature. Eye(Lond) 27: 787-794, 2013.

25. Hoerster R, Muether P, Dahlke C, Mehler K, Oberthür A, Kirchof B and Fauser S: Serum concentrations of vascular endothelial growth factor in an infant treated with ranibizumab for retinopathy of prematurity. Acta Ophthalmol 91: e74-e75, 2013

26. Simoncini T, Maffei S, Basta G, Barsacchi G, Genazzani AR, Liao JK and De Caterina R: Estrogens and glucocorticoids inhibit endothelial vascular cell adhesion molecule-1 expression by different transcriptional mechanisms. Circ Res 87: 19-25, 2000 .

27. Ma X, Bi H, Qu Y, Xie X and Li J: The contrasting effect of estrogen on mRNA expression of VEGF in bovine retinal vascular endothelial cells under different oxygen conditions. Graefes Arch Clin Exp Ophthalmol 249: 871-877, 2011.

28. Thompson LP, Pinkas G and Weiner CP: Chronic 17beta-estradiol replacement increases nitric oxide-mediated vasodilation of guinea pig coronary microcirculation. Circulation 102: 445-451, 2000.

29. Suzuma I, Mandai M, Takagi H, Suzuma K, Otani A, Oh H, Kobayashi K and Honda Y: 17 Beta-estradiol increases VEGF receptor-2 and promotes DNA synthesis in retinal microvascular endothelial cells. Invest Ophthalmol Vis Sci 40: 2122-2129, 1999.

30. Miyamoto N, Mandai M, Takagi H, Suzuma I, Suzuma K, Koyama S, Otani A, Oh H and Honda Y: Contrasting effect of estrogen on VEGF induction under different oxygen status and its role in murine ROP. Invest Ophthalmol Vis Sci 43: 2007-2014, 2002 . 
31. Takeyama J, Suzuke T, Inoue S, Kaneko C, Nagura H, Harada N and Sasano H: Expression and cellular localization of estrogen receptors and in the human fetus. J Clin Endocrinol Metab 86: 2258-2262, 2001

32. Gruber CJ, Tschugguel W, Schneeberger C and Huber JC: Production and actions of estrogens. N Engl J Med 346: 340-352, 2002.

33. Huppmann S, Römer S, Altmann R, Obladen M and Berns M: 17beta-estradiol attenuates hyperoxia-induced apoptosis in mouse C8-D1A cell line. J Neuro Res 86: 3420-3426, 2008.

34. Morles DE, McGowan KA, Grant DS, Maheshwari S, Bhartiya D, Cid MC, Kleinman HK and Schnaper HW: Molecular and cellular cardiology: Estrogen promotes angiogenic activity in human umbilical vein endothelial cells in vitro and in a murine model Circulation 91: 755-763, 1995.

35. Shi WJ, Chen C, Zhou GM, Hu BY and Xiao HL: The role of vascular endothelial growth factor, fibroblast growth factor- 2 and estrogen receptor in the pathogenesis of retinopathy of neonatal mice. Fudan Xue Bao Yi Xue Ban Bian Ji Wei Yuan Hui 34: 228-232, 2007 (In Chinese)

36. Trotter A, Maier L, Grill HJ, Kohn T, Heckmann M and Pohlandt F: Effects of postnatal estradiol and progesterone replacement in extremely preterm infants. J Clin Endocrinol Metab 84: 4531-4535, 1999.

37. Trotter A, Bokelmann B, Sorgo W, Bechinger-Kornhuber D Heinemann H, Schmücker G, Oesterle M, Köhntop B, Brisch KH and Pohlandt F: Follow-up examination at the age of 15 months of extremely preterm infants after postnatal estradiol and progesterone replacement. J Clin Endocrinol Metab 86: 601-603, 2001.
38. Trotter A, Maier L, Kohn T, Böhm W and Pohlandt F: Growth of the uterus and mammary glands and vaginal cytologic features in extremely premature infants with postnatal replacement of estradiol and progesterone. Am J Obstet Gynecol 186: 184-188, 2002.

39. McLaren J,Prentice A, Charnock-Jones DS, Millican SA, Müller KH, Sharkey AM and Smith SK: Vascular endothelial growth factor is produced by peritoneal fluid macrophages in endometriosis and is regulated by ovarian steroids. J Clin Invest 98: 482-489, 1996.

40. Kaja S, Yang SH, Wei J, Fujitani K, Liu R, Brun-Zinkernagel AM, Simpkins JW, Inokuchi K and Koulen P: Estrogen protects the inner retina from apoptosis and ischemia-induced loss of Vesl-1 L/Homer 1c immunoreactive synaptic connections. Invest Ophthalmol Vis Sci 44: 3155-3162, 2003

41. Xu J and Su H: Body surface area calculation method for humans and animals. In: Pharmacological Experiments.Yuanpei Zhang (ed.) Beijing Publication Group, Beijing, p241, 1996.

42. Yuen KK and Kahn HA: The association of femal hormones with blindness from diabetic retinopathy. Am J Ophthalmol 81: 820-822, 1976.

43. Porter JC: Hormonal regulation of breast development and activity. J Invest Dermatol 63: 85-92, 1974. 